\title{
Red meat demand in Saudi Arabia: Applied Study, 1988-2007
}

\begin{abstract}
Noura Saud Al-Harbi
Abstract:

This study aimed at identifying the determinants of demand for red meat in [he Kingdom of Saudi Arabia during 1988-2007. The rnethodology consisted of examining the data for stationarity and to-integration to avoid spurious regression. Ordinary-least squares methods were then adopted together with the partial adjustment hypothesis to estimate the demand function for red meat in the short and long run. The results indicated that the price of red meat relative to the price of fish and demand for red meat with one period lag are significant determinants of demand for red meat, Indeed, demand for meat in the previous period turned out to be the most important determinant of current demand for red meat. Income and price of red meat relative to the price of chicken were not statistically significant: Finally the long-run elasticity of demand for red meat with respect to all variables turned out to be far higher than their counterpart in the short run. These results arc in line with economic theory and dynamic models. Keywords: Red meat, KSA, dynamic models
\end{abstract}

DOI: $10.7176 / \mathrm{JESD} / 10-20-10$

Publication date:October $31^{\text {st } 2019}$

\section{Introduction:}

Saudi Arabia still needs red meat despite producing many other products as part of the kingdom's plan to achieve high levels of self-sufficiency and the country relies on more than 60 imports of red meat. Although Saudi Arabia is interested in the development of local production of red meat, the self-sufficiency ratio has decreased. Imports also increased at an annual rate of about 16 from an average in the period 1391-1406D and for this reason. Demand for red meat imports in the Kingdom of Saudi Arabia has gained importance due to the increasing proportion of imports of this commodity in food imports (Abdali, 2007).

This research aims to study the determinants of red meat demand in Saudi Arabia during the period 1988-2007. The study assumes that the demand for red meat in Saudi Arabia is influenced by economic and social factors. Economically, the study assumes that the demand for red meat in Saudi Arabia is influenced by income and the price of red meat relative to the prices of alternative commodities, mainly fish and poultry. Socially, the demand for red meat is influenced by factors related to an attempt by consumers to maintain previous levels of consumption. Hence, this study has gained importance in terms of the possibility of being used in the formulation of economic policies that can be followed and aims to bridge the deficit of that commodity and achieve food security for society..

The study was based on annual time series for the category 1988-2007 on model variables issued by the Ministry of Finance and the Ministry of Economic Planning. The determination of this period is mainly due to the lack of data on these variables for any other years, which prevented the use of contemporary methods to analyze those data. These analyzes were limited to examining the silence of time series of variables to avoid what is known as the problem of false regression. The least-squares method and the partial adjustment hypothesis were then used to estimate short- and long-term red meat demand functions.

The results showed that all time series of model variables are static, as they do not suffer from the problem of unit root. This means that they can be used and have non-false regressions. As well. The results of the AngelGranger test show that the time series of the variables are fully integrated, confirming that the regressions caused by the use of the least squares method are not false.

On the other hand. The least squares method and partial adaptation hypothesis were used to estimate the red meat demand function of Saudi Arabia in the short and long term. The results showed that the price of red meat as a percentage of the price of fish, in addition to the demand for red meat with a period of slowdown and sharpness. it has an effect.

\section{Seduced on demand for red meat:}

Specifically, the results showed that demand for red meat with a single slowdown was the most significant variable in terms of statistical significance in influencing the current demand for red meat. Income or the price of red meat as a percentage of the price of poultry had no significant effect on the demand for that commodity. Finally, based on the partial adaptation hypothesis, the results indicated that the logarithm of current demand for red meat adapts relatively slowly to the desired logarithm demand for red stars, and that the elasticities of demand for red meat for all variables are greater than their counterparts in the short term, which is consistent With economic theory and dynamic models.

The rest of the paper falls into five parts. In Part (2) we review the most important features of the Saudi economy with a focus on the agricultural sector, while in Part (3) we review the applied literature relevant to the subject of research. In Part (4) we deal with research methodology, including formulation of the theoretical model, data on model variables, as well as methods of data analysis. Applied results are discussed in Part 5. The paper concludes 
in part (6) with some concluding observations.

Features of the Saudi economy and the agricultural sector:

The population of the Kingdom has evolved considerably over the past four decades. The first census of the Kingdom was conducted in 1382/1962, with an estimated population of 33 million, but the state did not recognize the result of this census nor was it adopted because of the large proportion of the population (nomads) who were not counted in that census. Another census was conducted in 1394/1974 and the population was estimated at 7 million. In 2004, another census was conducted with an estimated population of 227 million. The last census was $2010 / 2010$, which estimated the total population of about 71 million people. This rapid population growth is due to two factors: natural increase (the difference between births and deaths) and abnormal increases (migration). For natural factors, birth rates rose. Mortality rates have also declined in health care and the elimination of many diseases, especially epidemic diseases such as smallpox, measles, cholera and others.

As for the abnormal increase, expatriate labor has played a big role in influencing the population of the Kingdom and their numbers have increased steadily during the past four decades. 4.2, to reach 9031 of the total population in 2010. The growth in expatriate employment is due to the expansion of infrastructure and the need to fill the labor market deficit caused by the fact that more than $50 \%$ of the Saudi population is under 20 years of age.

The overall agricultural pulse began in the Kingdom during the mid-seventies of the last century when detailed studies of water and land resources proved the existence of the desired agricultural development ingredients and the state has since focused on accelerating the support of other development pillars, drawing a tight agricultural policy aimed at advancing the agricultural sector and developing its capabilities with exploitation. Optimizing natural resources and achieving balanced development among all regions of the Kingdom.

Government intervention has had a major impact on the achievement of agricultural development objectives through various agricultural policy instruments such as subsidies, interest-free loans, free distribution of land, development of infrastructure support services and the advancement of roads, dams, silos, research centers, training and extension services.

The bank's agricultural loans in 2011 amounted to about SR 6255 million, an increase of SR 5 million compared to loans disbursed in 2010, which represents 80. The agricultural sector recorded a growth rate of 49 in 2011 compared to 14 in 2010. The agricultural GDP at current prices amounted to about 441 billion riyals compared to 42 billion riyals in 2010 to reach its contribution in the non-oil sector 48 and GDP 2. Available statistics from the Central Department of Statistics show that the output of the agricultural sector at constant prices rose from SR 39,466 million in 2007 to SR 410,086 million in 2011. Table 1 shows the growth rates in the agricultural sector during the period 2011-2007. Compared to other sectors.

Table 1: GDP growth rates by sector. 2007-2011

\begin{tabular}{|c|c|c|c|c|c|}
\hline \multicolumn{5}{|c|}{ Growth rates $(\%)$} & \multirow{2}{*}{ Clause } \\
\hline 2011 & 2010 & 2009 & 2008 & 2007 & \\
\hline 7,1 & 5,1 & 0,1 & 1,2 & 2,00 & $\begin{array}{l}\text { Gross domestic product } \\
\text { (constant 1999( }\end{array}$ \\
\hline 9.7 & 6.0 & 3.2 & 2.4 & 4.4 & Non-oil sectors \\
\hline 7.9 & 6.0 & 3.2 & 4.3 & 4.4 & Productive Sectors \\
\hline 2.8 & 1.1 & $0.5 \quad-$ & 0.7 & 1.8 & Agriculture, forestry and fishing \\
\hline 3.8 & 2.2 & 2.5 & 2.7 & 3.00 & Mining and quarrying \\
\hline 12.7 & 6.3 & 1.5 & 6.0 & 5.7 & Industry \\
\hline 5.2 & 7.9 & 6.8 & 6.7 & 4.1 & Electricity, gas and water \\
\hline 11.7 & 7.8 & 0.6 & 1.5 & 4.1 & building and Construction \\
\hline 6.7 & 6.2 & 4.3 & 4.5 & 4.3 & Services sector \\
\hline 7.1 & 8.5 & 2.5 & 6.5 & 6.2 & Trade, hotels ... etc \\
\hline 10.6 & 8.7 & 7.4 & 12.2 & 10.2 & $\begin{array}{l}\text { Transport, storage and } \\
\text { communication }\end{array}$ \\
\hline 3.2 & 1.6 & 2.7 & 2.8 & 4.4 & $\begin{array}{c}\text { Finance, Insurance and Real } \\
\text { Estate }\end{array}$ \\
\hline 9.4 & 5.9 & 4.0 & 2.4 & 2.7 & social services \\
\hline 6.3 & 6.8 & 5.0 & 2.4 & 1.9 & Government services \\
\hline 4.4 & 2.2 & 8.8 & 4.3 & $4.1-$ & Crude oil and natural gas sector \\
\hline
\end{tabular}

Source: Department of Statistics and Information.

Notes: $(*)$ Includes: oil refining, petrochemicals, and other manufacturing industries; 
The gross domestic product at current prices has witnessed a significant development and steady growth rates. Preliminary estimates indicated that the GDP at current prices has witnessed a growth rate of 863 in 2012 compared to 2011, as shown in Figure (207) that the Saudi economy achieves An annual increase in the value of GDP at current prices, where the period from 1970 to 2012 witnessed a clear increase in the value of GDP at current prices.

Figure (1) The evolution of GDP at current prices

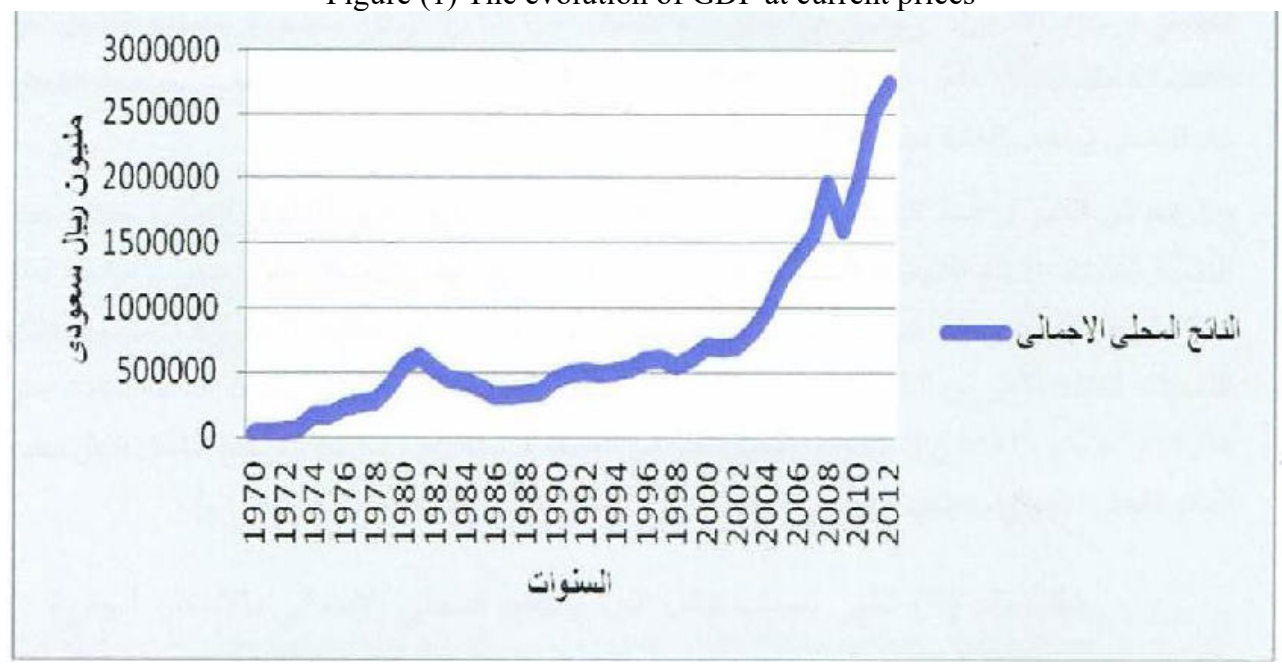

Source: According to the Department of Statistics and Information.

The growth rates of GDP have increased considerably, with the average annual growth rate at current prices reaching 14.69 during the period from 1970 to 2012, while the average growth rate during the period of the Eighth Plan and the beginning of the ninth 148 is higher than the overall average of successive plans. This is due to high oil prices during that period. Figure 1-7 shows the evolution of GDP growth rates at current prices during the period from 2002 to 2012 .

It is clear from the figure that the Saudi economy is achieving positive growth rates except in 2009, where the economy drew a negative growth rate of 1744 and accompanied by a decline in the global growth rate of 22 due to the global financial erosion and the consequent decline in oil prices.

Figure (2) The evolution of the GDP growth rate at current prices

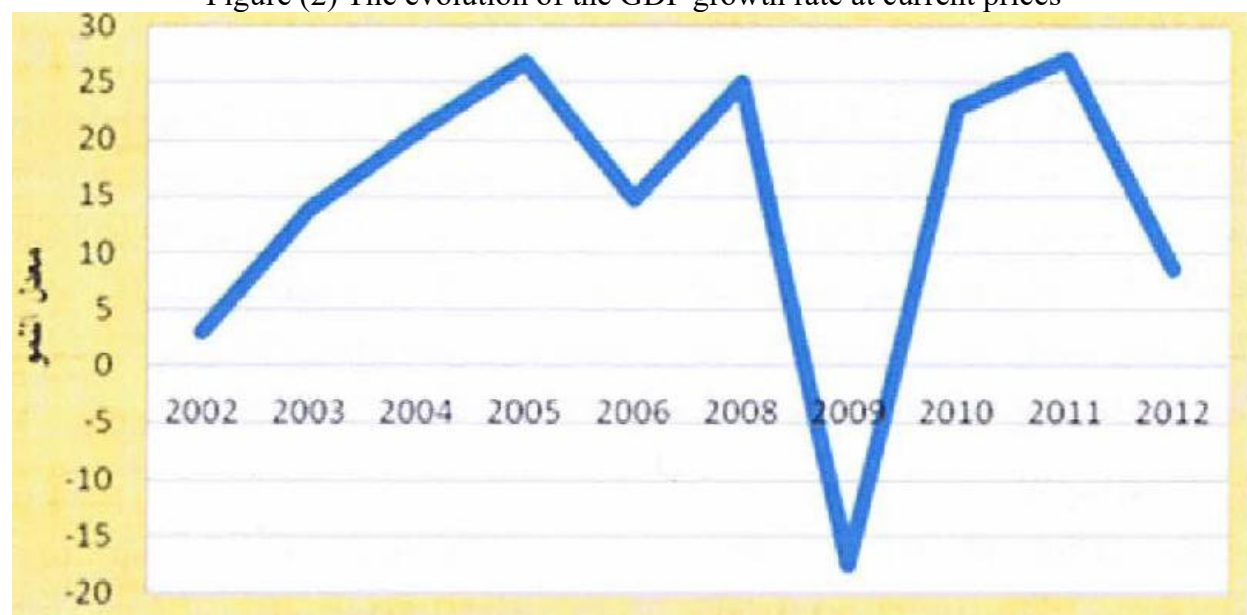

Source: Figure was drawn based on the Department of Statistics and Information.

Gross domestic product can be broken down by regulatory sectors, which are mostly oil and non-oil and import duties. This division shows the increase in the contribution of the oil sector from QR 820,881 million in 2010 to QR 1353569 million in 2012.In contrast, the contribution of the non-oil sector in the same period increased from QR 1079053 million to QR 1353729 million.

Despite the growth in the population, GDP per capita continued to rise during the Eighth Development Plan. The average annual per capita GDP during the plan years was about SR 61944, while the Ninth Development Plan increased the share of income. A steady increase during the first three years of the plan, where the average annual per capita income during the three years of the plan until 2012 about 84530 Saudi riyals with a growth rate from 
the Eighth Plan amounted to 3646 and the following figure shows the evolution of GDP and the share of GDP from GDP during the period 005 2012.(

Figure (3): Evolution in per capita income and GDP at current prices

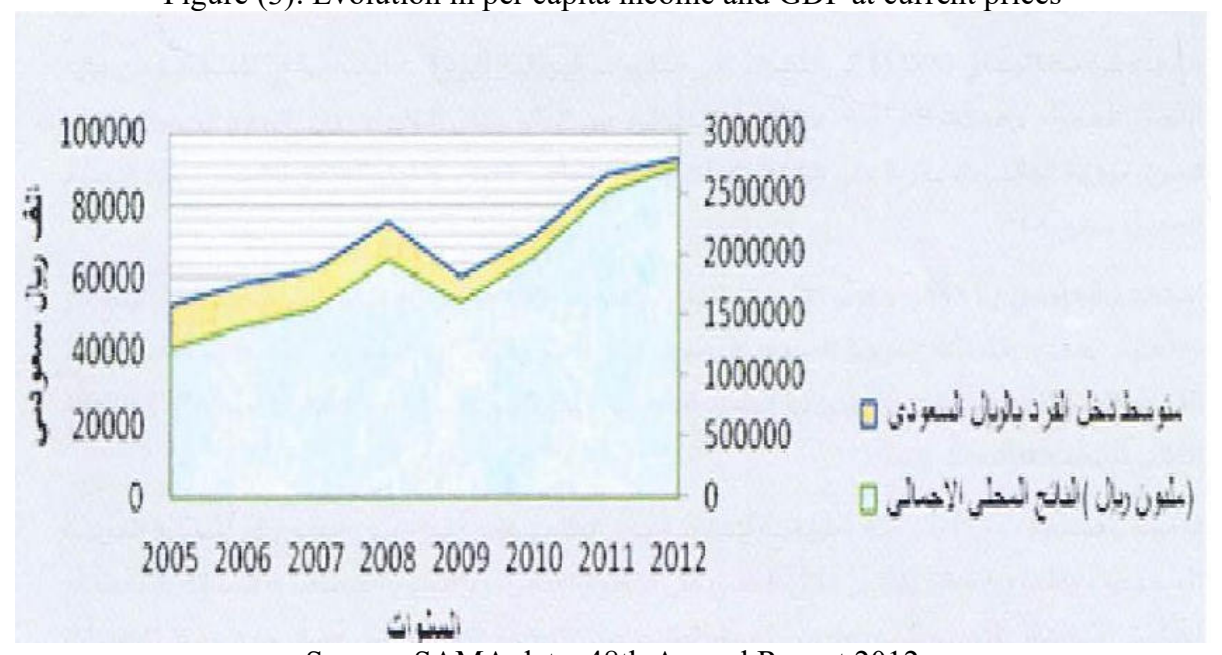

Source: SAMA data. 48th Annual Report 2012

The figure shows that the average per capita income is increasing annually in conjunction with GDP growth. The impact of the global financial crisis on oil prices, and with the beginning of the Ninth Development Plan until 2012, GDP returned to achieve an increase accompanied by growth in per capita GDP, where the per capita income of GDP in 2012 about 93420 Saudi riyals.

\section{Research Methodology:}

In this section we review the research methodology used in this paper. Specifically, in Part 14, we review the theoretical model for red meat demand, including the limitations imposed by economic theory on model indicators. In Part (24) we deal with the methodology of the study, which includes data for the ambassadors of the model in addition to the statistical and standard methods used in the analysis of those data. Specifically, we review the foundations of the Dickie-Fuller method for testing the silence of time series of model variables.

We also discuss the Angel-dragger method to test the common integration of these variables. As the time period covered by the study is relatively short, the available data on model variables are annual only. In section (4), our focus is on estimating a multiple short- and long-term standard model based on the partial adaptation hypothesis. We conclude the paper in Part (5) with some observations.

\section{Red Meat Order Form:}

There are many factors affecting tonnes on a good or service. In general, these factors can be classified into economic and social. Economic factors include, for example, the price of a commodity as a breath, the per capita income consumed, and the prices of other commodities, which can be alternative or complementary. Social factors include factors related to the customs and traditions of the society concerned.

Price is one of the most important economic factors affecting demand for goods. According to the law of demand, the demand for a good or service is inversely related to the price of the commodity, while other factors remain constant. The demand function of a commodity includes the prices of other commodities, which can be substitutes or supplements of the commodity concerned.

Which means Demand for the commodity in question is directly related to the price of the alternative commodity. As well. The demand for goods is influenced by the resources or economic potential of the consuming individual, usually measured by income. The effect of income on demand is calculated by the nature of a commodity. Which can be necessary or luxury, or from secondary goods .

As is well known, the rise in the price of the commodity can lead to the substitution of another commodity, which is known as the effect of substitution. On the other hand, high commodity price affects real income (economic potential) per capita. Which in turn affects the higher demand, which is known as income effect. In spite of the foregoing, analyzing the determinants of demand for some commodities can be difficult in practice. The most important difficulties in such studies are the multiplicity of alternative and complementary goods. In addition to difficulties related to the availability of data for such variables. Especially in developing countries. For these reasons, red meat supplements were excluded, while the focus was on only two substitutes of white meat. Are fish meat and poultry meat. Based on the above, for the purposes of this paper, we assume that the long-term demand function for Saudi Arabia's red meat takes the following formula.: 
whereas:

$$
Q_{1}=\beta_{0}\left(\frac{P R}{P C}\right)^{\beta 1} 1\left(\frac{P R}{P C}\right)^{\beta 2} 1 Y^{\beta 3} e^{u 1} \quad \beta_{1}<0, \beta_{2}<0 . \beta_{3}>0 .
$$

¿Q】_1 demand for red meat

PR Red meat price index

PF price of fish

PC Chicken Price Index

Real income per capita

For the purposes of estimating the model, we write it in the linear attribute in the logarithms, namely

$$
\operatorname{In} Q_{1}=\operatorname{In} \beta_{0}+\beta_{1} \operatorname{In}\left(\frac{P R}{P F}\right)_{1}+\beta_{2} \operatorname{In}\left(\frac{P R}{P C}\right)_{1}+\beta_{3} \operatorname{In} Y+\mu_{1}
$$

This is the linear formula for long-term red meat demand function, and assumes that long-term Q demand is a linear function in current variables of relative prices and income. As is known. The indicators of this function are elasticities for the length range. For example, B1 is the elasticity of demand for red meat relative to its price relative to the price of fish, B2 is the elasticity of demand for red meat relative to its price relative to the price of chicken B3 elasticity of demand for red meat for income in the long run. As long as permanent demand is not directly observed, there is a need to formulate a mechanism to devise it and then use it to obtain the self-regression, which is the short-term consumption function. For this purpose, we hypothesized the partial adaptation hypothesis (mass adaptation). As long as the long-term model takes the linear formula in.

For logarithms, the hypothesis of partial adaptation must take a linear formula in logarithms. In this case, it takes that for the hypothesis of the following formula.

$$
\frac{\mathbb{Q}_{1}}{\mathbb{Q}_{1-1}}=\left(\frac{\mathbb{Q}_{1}}{\mathbb{Q}_{1-1}}\right)^{\delta} \quad 0<\delta \leq 1
$$

Equation (3) shows that a fixed percentage of the difference between real (current) and desirable demand for red meat can be covered (achieved) over a period of time (eg a year, if the data is annual). To convert the partial adaptation formula by equation (3) to a linear formula in logarithms, we get.

$$
\operatorname{In} Q_{1}-\operatorname{In} Q_{1-1}=\delta\left(\operatorname{In} Q_{1}-\operatorname{In} Q_{1-1}\right)
$$

Which can be written in the following formula after rearranging the boundaries:

$$
\text { In } Q_{1}=\delta \text { In } Q_{1}+(1-\delta) \text { In } Q_{1-1}
$$

By substituting equation (2) in equation (4) and rearranging the boundaries we get:

$$
\operatorname{In} Q_{1}=\delta \operatorname{In} \beta_{0}+\delta \beta_{1} \operatorname{In} \frac{P R}{P F_{1}}+\delta \beta_{2} \operatorname{In} \frac{P R}{P C_{2}}+\delta \beta_{3} \operatorname{In} Y+(1-\delta) \operatorname{In} Q_{1-1}+v_{1} \quad v_{1}=\delta \mu_{1}
$$

This is the function of demand for red meat in the short term, and when it takes the self-regression formula

\section{Standard methods :}

The study is based on an annual time series of data on the above variables limited to the period 1988-2007 due to the lack of data for any other period according to the source of those data. The small sample size caused by the scarcity of available data has not given rise to contemporary methods of time series analysis, such as error correction models. The analysis was limited to the De-Fuller test of the silence of time series to avoid falling into a false regression trap.

\section{Time series sleep test:}

Many time series of economic variables are characterized by non-stationarity, a situation in which the mean of the series is variance, or the variance between any two values of the series changes in an upward or downward direction with time. Non-static time series lead to what is known as a purious regression. Which means that the link between them is not real, but because of the connection of everyone with time. For this reason, sleep options must be made for any time series before they can be used to estimate the model. Some of the most common tests are known as the Dickey-Fuller test and the Augmented Dickey-Fuller test. As is well known, the Detti Fuller test for the time series 2 sleep test is to estimate the following autistic regression.

$$
\gamma_{1}=\rho \gamma_{1-1}+\varepsilon_{1}
$$

We then test the null hypothesis versus the alternative hypothesis. Acceptance of the null hypothesis means that the chain is not static, whereas acceptance of the alternative hypothesis necessarily implies that the chain is static. Ability to estimate the above regression in several different formats, such as adding a breaker to the previous equation, adding a time vector, or adding both.

These hypotheses are tested using the conventional method, where we estimate the regression by equation (6) and get the calculated value of 4 and compare it to the tabular value of $t$ at the predetermined level of significance. 
If the calculated value is greater than or equal to the tabular value we accept the alternative hypothesis, and we conclude that the time series in question is static. vice versa. However, this method of choosing not to remain silent in the time series has many problems, summarized as follows (see: Mehran, 2015)

Firstly. We know that the appearance of the slower dependent variable on the right side (such as a floating variable) means that the estimation of the least squares is biased down to the small samples. The calculated test statistic is unreliable. Which means that the time series. Y1 is static while it is not Second. If the null hypothesis H0: $p=1$ is correct and the time series y1 is not static, the normal normal distribution results for large samples are incorrect. In other words, the test statistic cannot be relied on for medical distribution, even in the case of large samples. The distribution of calculated test statistics is not standard, and in fact is not uniform.

These problems were addressed by Dickey and Fuller (979, Dickey and Fuller). By reformulating the test equation as follows

$$
\Delta \gamma 1=\alpha+\delta \gamma 1-1+\mu 1 \quad \delta=(p-1)
$$

The null hypothesis is H0: $\delta$ while the alternative hypothesis is $0<\mathrm{H} 0: \delta \mathrm{We}$ reject the null hypothesis (and the time series is static) if the calculated statistical value $(\mathrm{t})$ is highly negative (the absolute value of this statistic is greater than the absolute value of the two tabular values). However, the test equation (7) above also has some problems. Specifically, if the Y1 time series is not white noise or is a higher degree of self-regression, then one of these possibilities could lead to a self-correlation problem between the random limits of the test equation in (7) above. Under these circumstances. The normal Dickie-Fuller method becomes unsuitable for testing the silence of the time series.

To address that problem, two methods were suggested. The first method is to maintain the test equation (7) as it is with adapting Dickey Fuller's statistic to allow for random self-bounding limits. The second method is to modify the test method to take the test equation in (7) above by a general formula by adding limits to the right side of the equation including differences for the variable involved in a number of decelerations. The second method leads to what is known as the enhanced Dicky Fuller test (ADF, test Dickey-Fuller Augmented). The reason for this designation is that the variable interpreted by the test equation (7) is reinforced by adding limits to the right side of the above equation, which include differences for the variable involved in a number of decelerations. In this case, the test equation takes the following formula

$$
\Delta \gamma_{1}=\alpha+\delta \gamma_{1-1}+\sum_{i=1}^{m} \alpha_{1} \Delta \gamma_{1-i} \varepsilon_{1}
$$

The advantage of the formula for the test equation in (8) above is that the idle chain test of the degree of slow $(\mathrm{m})$ in equation (3) is equivalent to testing whether (6) is in equation (8) above. It, as before. The null hypothesis remains that the time series has unit walls (ie, non-static), specifically, the null hypothesis in the enhanced DickieFuller test takes the formula $\mathrm{H} 1:=0$, while the alternative hypothesis takes the formula $0<\mathrm{H} 1: \delta$

As we have noted before, one of the problems of the enhanced Dick-Fuller test is "... the lack of prior knowledge of the degree of self-regression that fits the time series under study. In other words, the problem is not knowing the number of slowing limits of the variants of meaning to be added to the side. In practical and practical terms, the basic idea is to include as many slower boundary differences as possible so that the random limit of the equation (8) becomes autonomous As is known. The Lagrange multiplier is used to test the self-correlation between random boundaries. If Lagrange's self-correlation statistical value is weak, this is an indication of the need to add more slowing boundaries to the breaches of the variable involved. As with the Dickie-Fuller test, you can include the Dickie test equation. The enhanced Fuller is only a categorical, or a categorical and a direction of time, and the equation can be without a categorical and without time direction "(Mehran, 2015 )

An important concept is associated with the concept of the silence of the time series, which is known as the integration of the time series. The following explains this concept and how to identify whether it was an integrated time series, as well as the degree of that integration. If we take the first difference $\left(\Delta \gamma_{-} 1\right)$ of the time series $\left(\gamma_{-} 1\right)$ and the first difference series $\left(\Delta \gamma_{-} 1\right)$ is static. The original series $\left(\gamma_{-} 1\right)$ is said to be first order integrated. And you write (1) I. As well. If we take the second difference $\left[\Delta\left(\Delta \gamma_{-} 1\right]\right.$.) (Ie the first difference), for a time series $\left(\gamma_{-} 1\right)$ and the second difference series is static..

I write (2) I. In general, if we take the difference for a time series d times and the time series for $d$ is static, the original series is said to be an integral class d (intcgratcd of order d). And write (d) I. Finally, if the original time series $\left(\left(\gamma_{-}\right)\right.$is static without having to convert it to any difference to become static $(04)$, that (original) series is a zero-degree integral, ie (0) I. Therefore, if the time series is integrated The first or more of the original series are non-static.

In short, the concept of time series integration is related to the concept of stillness. If the time series is static (whether the series in question is the original series or its differences), that series is complementary. The concept of the degree of integration of the time series is related to the number of times we take the difference (d) to become static. If the original series is static without having to take its differences $(d=0)$, that series is a zero-integral I 
series. Thus, it should be noted that some time series remain non-stationaly regardless of the number of differences. These strings are said to be non-integrated.

Joint Integration: Engle- Granger Cointegration est:

Note that the random variable runs. For regression by equation (1) it can represent a linear union between model variables. The linear union between these variables is written in the following formula:

$$
\mu_{1}=\operatorname{In} Q_{1}-\operatorname{In} \beta_{0}-\beta_{1} \operatorname{In}\left(\frac{P R}{P F}\right)_{1}-\beta_{2} \operatorname{In}\left(\frac{P R}{P C}\right)_{1}-\beta_{3} \operatorname{In} \gamma_{1}
$$

If the line union between model variables is static, we can conclude that there is a common complement between those variables. So the question now is: how to examine whether the linear union of model variables is static? Several methods have been proposed to conduct a co-integration test between two variables of the model.

Regarding co-integration testing using Dickey-Fuller selection of unit root. So, all it takes is to run the model from which we calculate random boundary estimates. "And then run a Dickey-Fuller string test $\mu_{-} 1$ This test requires a gradient estimate:

$$
\Delta u_{1}=y u_{1-1}
$$

If $\mathrm{u} 1$ is a zero-degree integral, that is $(0) \mathrm{I}$, the linear union between the two variables is a zero-degree integral series, which means that it is a static string. In this case, the model variables are said to be cointegrated. That is, each of the variables moves in conjunction with the other variables, or they move (a in equation (10) integrated zero), that is, on the same wavelength (wavelength). The time trends of the variables of model J (1) cancel each other out, and the variables are at the same wavelength if each of them is the same degree.

In general, if each of the interpreted variables is complementary to the same degree (d). Variables can be jointly integrated. If that is the case, the regression of these variables is not false. You will not lose any valuable information over the long term, as in the case of the use of first degree differences instead of the original variables

Finally, there is a note to be taken into account regarding the calculated (t) statistics of the test equation indicators. In this regard, as long as the estimate $\left(\mu_{-} 1\right)$ is based on estimates of indicators of co-integration that. B_1, $\mathrm{i}=1,2,0000 \mathrm{k}$ The tabular values of the calculated deck-fuller statistics estimates as well as the tabular values of the enhanced Dick-Fuller test stats become inappropriate. Angel and Granger recalculated those critical values. This is why the Dickey-Fuller test in this context became known as the Angel-Ginger test.

\section{Model estimation: indirect least squares method :}

After checking the silence of the time series of all variables, and the co-integration between them, the indirect least squares method can be used to estimate the model. specially. Assuming that the random limit $\mu_{-} 1$ of the longterm model meets all classical objections, the random limit of $v_{-} 1$ for the short-term model meets those assumptions. In this case, the indicators of the autistic regression model can be estimated by equation. 5 Using the micro-sales method to obtain short-term indicators. Therefore, we use short-term indicators to retrieve the longterm indicators of the model in equation (1). In this regard, from the Q_ (1-1) index we get an estimate (I- $\delta$ ) from which to calculate the value of $\delta$ using this value and estimates of the indicators of the rest of the variables in equation (5) can be calculated both $\beta \_1 \beta \_2 \beta \_3$ Also, can be calculated $\beta \_0$ using an anti-logarithm estimate The equation (5). The long-term model is therefore estimated by equation (1)

Applied results:

Regardless of the formula taken by the model, it became necessary to subject the time series used in estimating standard models to the tests of the silence of those series before proceeding to estimate these models. So, as part of our model, we examine the silence of the throw chain of logarithmic formulas for both the demand for red meat.

The real per capita income, the prices of both red meat, fish and poultry. In addition to the price of red meat as a proportion of fish price of the drug. , All on select. The table below shows the results of the art of price of the D - Fuller unit root tests. The results in this table indicate that all time series of the model variables are static based on the enhanced Dickey-Foller test, where the test equation contains a breaker and a direction, and that all variables are integral from zero. 


\begin{tabular}{|c|c|c|c|c|c|c|}
\hline \multicolumn{7}{|c|}{ Dickey - Fuller Enhanced Static Variability Test } \\
\hline \multirow[t]{3}{*}{ Variable } & & & & & & \\
\hline & \multicolumn{3}{|c|}{ Variable level) $\operatorname{In} Z($} & \multicolumn{3}{|c|}{ The first difference of the variable $) \Delta \operatorname{In} Z($} \\
\hline & Cutter & $\begin{array}{l}\text { cutter and } \\
\text { direction }\end{array}$ & $\begin{array}{l}\text { Without cutter and } \\
\text { direction }\end{array}$ & cutter & $\begin{array}{l}\text { cutter and } \\
\text { direction }\end{array}$ & $\begin{array}{l}\text { Without } \\
\text { cutter and } \\
\text { direction }\end{array}$ \\
\hline In $D E M$ & $2.1394-$ & 0.6864 & $1.0376-$ & $1.6216-$ & $4.3875-$ & $1.5749-$ \\
\hline In $Y$ & $6.8265-$ & $5.7725-$ & $1.3228-$ & $3.5279-$ & $3.8648-$ & $3.7509-$ \\
\hline $\operatorname{InPRC}$ & $1.7920-$ & $2.2068-$ & $1.9501-$ & $3.4681-$ & $3.3423-$ & $3.4255-$ \\
\hline $\operatorname{InPRF}$ & $0.2034-$ & $2.3013-$ & $0.4657-$ & $5.8193-$ & $6.0136-$ & $5.5307-$ \\
\hline $\operatorname{InPR}$ & $0.2289-$ & $2.7776-$ & 3.6353 & $3.8058-$ & $3.7061-$ & $2.9345-$ \\
\hline $\operatorname{InPC}$ & 0.0858 & $2.5293-$ & 2.9691 & 3.9783 & $4.3743-$ & $3.1266-$ \\
\hline$I n P F$ & 7600.0 & $3.9520-$ & 2.9912 & $4.0067-$ & 4.1091- & $3.1570-$ \\
\hline
\end{tabular}

We now proceed to estimate the short-term red meat demand function by equation (5). for this purpose. Used The least squares method on the linear formula in the logarithms is to get two slopes, one by a section and the other without a one, respectively:

) 11(

$$
\begin{array}{llllll}
\multicolumn{9}{c}{\operatorname{In} Q=-3.1401-0.6535 \operatorname{in} \frac{P r}{P f}-0.1273 \operatorname{In} \frac{P r}{P c}+0.3463 \operatorname{In} Y+0.9711 \operatorname{In} Q_{1}} \\
\mathrm{~T} & (0.8407) & (1.606) & (0.2510) & (02510) & (0.8850) \\
\mathrm{P} & (0.4100) & (0.0769) & (0.8043) & (0.3862) & (0.0000) \\
\mathrm{R}^{2}=0.822 & \mathrm{~F}=24.2072 & \mathrm{~d}=2.231
\end{array}
$$

White $X^{2}(4)=3.640852$ [ $\left.p=0.456\right]$ LM X $^{2}$ (1) $0.494760[p=0.4818] J B=105144[p=0.4690]$

) 12

$$
\operatorname{In} Q=-0.7258 \operatorname{In} \frac{P r}{P f}-0.2359 \operatorname{In} \frac{P r}{P c}+0.0481 \operatorname{In} Y+0.9676 \operatorname{In} Q_{1}
$$

$\begin{array}{lllll}\mathrm{T} & (2.1454 & (0.4873) & (0.2931) & (8.0629) \\ \mathrm{P} & (0.0432) & (0.6330 & (0.7722) & (0.0000)\end{array}$

$\mathrm{R}^{2}=0.816 \quad \mathrm{~d}=2.197$

White $X^{2}(4)=3.641736[\mathrm{p}=0.4837] \mathrm{LM} \mathrm{X}^{2}(1) 0.4775[\mathrm{p}=0.4896] \mathrm{JB}=1.6133[\mathrm{p}=0.4464]$

We now turn to discuss these results. We first examine the diagnostic tests for these regressions. As is well known, the models of self-regression are exalted from the problem of variation of the variation of random boundaries, as well as the problem of self-correlation between these limits. However, diagnostic tests of these models show that these regressions do not suffer from these problems. specially. A quadratic statistical value for the White With test of random variation variation (without intersecting variables) indicates that both models do not have this problem (Lagrange's multiplier) of the Brooch-Godfrey-Pagan test indicates that these models do not also suffer from the problem of first-order self-correlation between random boundaries, which is confirmed by the Durban-Watson statistic value of the two models as well. For regressions not normal distribution. Finally, the value of the coefficient of determination and statistic 3 indicates that independent variables account for more than 80 percent of the dependent variable and that these variables have a significant effect on the dependent variable simultaneously.

On the other hand, all indicator estimates for these models indicate that the predicted signals are taken according to economic theory, but we are not statistically significant, except for the sluggish variable, whose significance was high for all models, and the relative price of red meat with fish in equation (12). In sum, all these declines clearly indicate that the demand for red meat in the current period is greatly affected by the demand for red meat in the previous period. This demand is not affected by real per capita income or the relative price of red meat and chicken. With the exception of regression in (11). Regression in equation (12) indicates that demand for red meat is also affected by the price of red meat relative to the price of fish. We conclude that regression by equation (12) is best based on diagnostic tests and consistency of results with theory. What do results mean by equation (8)? In the light of the short-term model of equation (8), $\delta$ is the adjustment coefficient.

It can be calculated from the estimation of the coefficient of the explanatory variable with a single deceleration period in equation (12). Let's get

$=1-0.9676=0.0324) \delta$. In the light of the partial adaptation hypothesis of equation (4) This result means that about 3 percent of the difference between the logarithm of the terrified demand and the logarithm of current demand for 
red meat fades within one year, which also means that Logarithm The current demand for red meat adapts relatively slowly to the desired logarithm for red meat.

$$
\operatorname{InQ}=-22.4012 \mathrm{IN} \frac{P r}{P f}-7.2809 I N \frac{P r}{P C}+1.4846 I N Y
$$

Clear from these results that the elasticity of demand for red Allho in the long term for relative prices and income is much greater Amzehe in the short term, which is consistent with the dynamic model used in the analysis. This section concludes by conducting the Angel-Granger test for the common integration of the regression variables above. The idea of this test is based on the Dick-Fuller Root Unit test. All it takes is the estimation of the model of interest and calculation of random boundary estimates, and then a Dickey-Fuller test on the $\mu$ series. If $\mu$ is a static string, I am said to be a zero-order integral, i.e. (0) i, and the linear union of model variables is a zeroorder integral series, in which case the model variables (dependent and interpreted) are said to be co-integrated (cointcgrated). . Which means that each of these variables moves in conjunction with other variables. Or they move at the same wavelength. A priori. If $\mu$, is an integral degree of zero, i.e. (0) i. This means that the temporal trends of variables cancel each other out, and the variables are on the same wavelength if each is the same degree. In general, if both model variables are equally integrated (d), those variables can be integrally integrated. And if that is the case. The regression that includes these variables is not false. You will not lose any valuable information over the long term when compared to the case of using first-rate differences instead of the original variables. The table below summarizes the results of the Angel Granger test for the common integration of the regression variables above. Based on equation (6).

\section{Angel-Granger test results for co-integration}

\begin{tabular}{|c|c|c|c|c|c|c|}
\hline \multirow{2}{*}{ Sample } & \multirow{2}{*}{$\boldsymbol{*}$} & \multirow{2}{*}{$\boldsymbol{i}$} & & \multicolumn{3}{|c|}{ Statistical Quinon is a tabular by level of significance } \\
\cline { 5 - 7 } & & & & 0.01 & 0.05 & 0.10 \\
\hline 2 & $1.1191-$ & $5.5061-$ & 1.9447 & $2.660720-$ & $1.955020-$ & $1,607070-$ \\
\hline 4 & $1.1146-$ & $5.5168-$ & 1.9472 & $2.660720-$ & $1.955020-$ & $1.609070-$ \\
\hline
\end{tabular}

It is clear from these results that the absolute value of the calculated $\tau$ statistic is greater than the values of the McKinnon tabular statistic at all the significance levels. Thus, we conclude that these results clearly indicate a common integration of all the variables contained in each of the regression. This means that the results obtained in these regressions are not false.

\section{Concluding remarks:}

The problem of the study was to determine and estimate the demand function of red meat in Saudi Arabia for the period 1988-2007. Identify the determinants of that demand. The least-squares method and the partial adjustment hypothesis were then used to estimate short- and long-term red meat demand functions. The results showed that all time series of the model variables are still, and the results of the Angel-Granger test She pointed to the common integration of time series of variables, confirming that the regressions caused by the use of the least squares method are real and not false. The least squares method and the partial adjustment hypothesis were then used to estimate the red meat demand function of Saudi Arabia in the short and long term. The results showed that the price of red meat as a percentage of the price of fish. In addition to the demand for red meat with a single slowdown period, it has a statistically significant effect on the demand for red meat. The results also showed that the demand for red meat with one slowdown period was the most significant variable in terms of statistical significance in influencing the current demand for red meat. On the other hand, the results also showed that the income or the price of red meat a pile of poultry price had no significant effect on the demand for that commodity. Finally, based on the premise of partial adjustment. The results indicated that the logarithm of the current demand for red meat is slowly adjusting, forgetting the logarithm of the desired demand for red meat . The elasticity of demand for red meat for all variables is greater than in the short term, which is in line with economic theory and dynamic models.

\section{References:}

1- Abdali. Abid bin Ayed (207), Renewal of the Demand for Imports of Saudi Arabia in the Context of Joint Integration and Correction of Error, Journal of the Salej Kamel Center for Islamic Economics. Al-Azhar University, Number (23).

2- Summary Report of the Eighth Development Plan, Ministry of Planning and Economy, Saudi Arabia, 2005 2005.

3- Abu Al-Saud, Mahmoud Fawzi (2004), Introduction to Macroeconomics. Durr University. Alexandria. 4- Anani. Hamdi Ahmed (1995) Introduction to Macroeconomics. (Cairo, Lebanese Banking House).

5- Al-Wazani, Khalid Al-Rafati Ahmad (2003). Macroeconomic principles between theory and practice. Wael Publishing House. 
6- Ayoub. Samira (2000), International Monetary Fund and the issue of economic and financial reform. Evaluative Analytical Study Alexandria, Alexandria Book Center.

7- Suleiman Magdy (2002) the treatment of inflation and economic stagnation in Islam (Cairo Dar Gharib for printing, publishing and distribution).

8- Summary Report of the Ninth Development Plan, Ministry of Planning and Economy, Saudi Arabia.

9- Manzulawi, Khalid Mohammed Khalil (2006), "Intra-GCC Trade, Its Importance, Growth and Influencing Elements", Master Thesis, Faculty of Economics and Administration, King Abdulaziz University.

10- Al-Khuraiji, Abdullah Ali (1996). Determinants of Free Trade and the Balanced Shift in Intra-GCC Trade, GCC Cooperation Journal, Issue No. 41, p.

11- Economic Bulletin, General Secretariat of the Gulf Cooperation Council, No. 10, Riyadh, 1995. P. 53.

12- The Secretary. Pasha Abdul Wahab, Zakariya Abdul Majeed (1983). Principles of Economics. part two. total economy . Knowledge House. Kuwait.

13- Maatouk, Suhair Mijmoud (1990), Economic stabilization policies, contemporary Egypt (419-420), Cairo, April 1990.

14- Mehran, Hatem Amir (2015): Memoirs of Econometrics. Department of Economics. Imam Muhammad bin Saud Islamic University, Riyadh, Saudi Arabia.

15- Saudi Monetary Agency. Economic Reports and Bulletins, http://www.sama.gov.sa./

16- Saudi Ministry of Economy and Planning. https://www.mep.gov.sa

17- Saudi Ministry of Finance, https://www.mof.gov.sa.

18- Aljebrin, Mohammed Abdullah (2012) "The Determinants of the Demand for Imports in GCC Countries" College of Administrative Sciences and Humanities, Majmaah University.

19-Al-Dakhil, \& A1-Yousef N. (r t). Aggregate import demand function for Saudi Arabia: An error correction approach. Journal of Economic \& Administrative Sciences, 18,83-100.

20-Alias, H. M., \& Tang. T. C, (2000) Aggregate imports and expenditure components in Malaysia; A counteraction and error correction analysis. ASEAN Economic Bulletin, 17,257-69 http://dx.doi.orgh/10,1355/AE17-3B.

21-Arab monetary Fund (AMF) Arab Monetary Fund (AMF) http://www.amf.org.ae/ctrylisten/45/foreign\%Trade. 22-Bahmani-Oskooee, M. (1988) Cointegration approach to estimate the long-run trade elasticiries in LDCs , International Economic Journal,12,89-96.

23-Breitung, (2000) ,The local power of some unit root tests for panel data. In: Baltagi, B, Fomby,T.B Hill, R.C. (Eds.), Advances in econometrics: no stationary date, panels panels Cointegration and Dynamic Panels, 15,161,78. 24-Carone, G. (1996). Modeling the U.S demand for imports through counteraction and error correction, Journal Of Policy Modeling, 18,1-48 http:/dx.doi.org/10,1016/0161-8938(95)00058-5.

25-Dickey, D.A and WA. Fuller (1979): "Distribution of the Estimators for Autoregressive Time Series with a Unit Root", Journal of the American Statistical Association,Vol 74. Pp.427-431.

26-Doroodian, et al (1994). An examination of the traditional import demand function for Saudi Arabia,Applied Economics,26,909-915.

Http://dx.doi.org/10.1080/000368494000000052

27-Dutta, D, \& Ahmed. N. (2006). An aggregate import demand function for India A counteraction analysis. School of Economics and Political Science, University of Sydney, Australia. Retrieved from https: digitalcoIIections.anu-edu.au/handle/1885/40314. 